\title{
An Experimental Method of Distribution Behavior of Hydrophobically Associated Polymer AP-P4 in Three-Phase Systems
}

\author{
Ruyin Li, ${ }^{1,2}$ Guorong Tan, ${ }^{1,2}$ and Jian Zhang ${ }^{1,2}$ \\ ${ }^{1}$ State Key Laboratory of Offshore Oil Exploitation, Beijing 100027, China \\ ${ }^{2}$ CNOOC Research Institute, Beijing 100027, China \\ Correspondence should be addressed to Ruyin Li; liry3@cnooc.com.cn
}

Received 20 February 2013; Revised 8 April 2013; Accepted 8 April 2013

Academic Editor: Yujun Feng

Copyright (C) 2013 Ruyin Li et al. This is an open access article distributed under the Creative Commons Attribution License, which permits unrestricted use, distribution, and reproduction in any medium, provided the original work is properly cited.

A novel experimental method has been established for the first time to evaluate the distribution behavior of water soluble hydrophobically associated polymer AP-P4 in the oil-water-solid three-phase systems, based on the static adsorption principle. Suitable analysis method has been selected to measure the concentration of polymer in every phase. The enrichment of polymer has been observed between the oil-aqueous interlayer. The distribution coefficient of AP-P4 is obtained along with the variation of concentration and total salinity. The experimental method is helpful to reveal the property of polymer solution and has potential usage in predicting the adsorption and retention in polymer flooding and the wastewater dealing of polymer flooding.

\section{Introduction}

Polymer flooding has been widely used as one of the most important stimulation treatments in oil fields. Different from the ordinary polymers, the hydrophobically associated polymer has significantly exhibited the ability to enhance the viscosity, to modify the water/oil mobility ratio, to reduce the water permeability, and to enlarge the swept volume in the formation [1-3]. AP-P4 as one kind of hydrophobically associated polymer has been widely used in the oilfields and its driven process is assisted by several different environmental factors. The polymer molecules could be distributed in the formation, aqueous phase, oil phase, or emulsion phase after injection, and each of them could exhibit different adsorption and transfusion behavior. Plenty of works have been done on the static and dynamic adsorption principle of polymer AP-P4 under various concentrations $[1,4-14]$, and the properties of rheology, viscoelasticity, thermoendurance, salt tolerance, and shear degradation have been chartered. It has been revealed that the associated function group could be different from the linear polymer while adsorption [15]. The effective permeability could be lowered sharply after injection of polymer solutions, no matter the value of porosity of the formation $[9,15,16]$. However, the traditional adsorption experiments of AP-P4 were carried out on aqueous/solid phase, and the results of these experiments could only reflect the adsorption and retention behavior between two-phase systems. The model is too simple to find out the influence of concentration loss of polymer solutions. In polymer flooding process, most polymer molecules with hydrophobic function groups would exhibit the trend to get out of aqueous phase. Under the nonpolar interaction of oil phase, the polymer molecules would be likely to stay at the interlayer between aqueous and oil phases. The concentration of polymer in aqueous phase would be thus reduced. Although the composition of hydrophobic function group may be low, the effects of oil phase could not be neglected on AP-P4. However, there is no measurement method to estimate the polymer concentration in oil phase as far as we know and so does the polymer concentrations enriched at the oil/aqueous interlayer. So it is important to design an experiment method to analyze the distribution behavior of polymer among oil/aqueous/solid three-phase systems.

A novel experiment method of oil/aqueous/solid threephase systems was designed in this work, in order to reveal 
TABLE 1: The components of simulative water of SZ 36-1.

\begin{tabular}{lcccccc}
\hline & $\mathrm{NaCl} / \mathrm{mg} \mathrm{L}^{-1}$ & $\mathrm{NaHCO}_{3} / \mathrm{mg} \mathrm{L}^{-1}$ & $\mathrm{Na}_{2} \mathrm{SO}_{4} / \mathrm{mg} \mathrm{L}^{-1}$ & $\mathrm{CaCl}_{2} / \mathrm{mg} \mathrm{L}^{-1}$ & $\mathrm{MgCl}_{2} \cdot \mathrm{H}_{2} \mathrm{O} / \mathrm{mg} \mathrm{L}^{-1}$ & $\mathrm{Total} \mathrm{salinity/mg} \mathrm{L}^{-1}$ \\
\hline Simulative water, A & 7461 & 430 & 304 & 192 & 352 & 8739 \\
Simulative water, B & 14922 & 860 & 608 & 384 & 704 & 17478 \\
\hline
\end{tabular}

the trace, enrichment behavior, equilibrium state of polymer molecules after the solution was injected. Besides, a novel measurement method was designed to evaluate the polymer concentration in oil phase. The effect of oil phase could be estimated by this method, through the comparison of threephase and two-phase experiment results.

\section{Experiment}

\subsection{Materials and Instruments}

Solid-Phase Sorbent. Pure quartz sand (100-160 mesh) was washed by deionized water and then dried.

AP-P4 Powder. $M_{\mathrm{W}}=1 \times 10^{7}$, degree of hydrolysis $25.3 \%$.

Crude Oil. From SZ 36-1 oilfield, after electric dehydration.

Chemicals. $\mathrm{NaCl}, \mathrm{CaCl}_{2}, \mathrm{MgCl}_{2}, \mathrm{NaHCO}_{3}, \mathrm{Na}_{2} \mathrm{SO}_{4}$, solution of $\mathrm{CH}_{3} \mathrm{COOH}$, solution of $\mathrm{NaClO}$, deionized water, and so forth.

Demulsifier and Electric Dehydration Performance Tester (DPY-2C, Jiangsu analytical instrument factory).

COD digestor and UV-Vis Spectrophotometer.

\subsection{The Method to Measure the Concentration of AP-P4} Solution in the Oil Phase and Aqueous Phase. The distribution coefficient of AP-P4 could be determined by analyzing the concentration of AP-P4 in oil, water, and solid phases when the system reaches the equilibrium.

When crude oil, water, and quartz sand were coexisted and reached the phase equilibrium, the three layers were in the hierarchical mixture of state. Crude oil located in the upper layer; in the middle there were water and quartz sand soaked at the bottom of water phase. In order to measure the concentration of AP-P4 in each phase, we need to perform phase-separation operation. After we determined the polymer content in at least two phases, we were able to understand the partition law of the polymers among three phases. After phase separation, the polymer concentration in water phase can be directly measured while those in oil phase and quartz sand cannot.

Considering that polymers are easy to dissolve in water, and their solubility in crude oil is rather small, in this work, we select deionized water, a good solvent for AP-P4, as extractant, and mix it with the same amount of oil phase containing AP-P4, and heat them until the phase equilibrium is reached, then through liquid extraction, the aqueous phase can be obtained. Then the AP-P4 content can be qualitatively determined by total nitrogen nephelometry. Repeat the oil extraction operation until the polymer is completely transferred from the oil phase to water phase. Lastly, merge all water phases and measure the AP-P4 concentration so that the polymer concentration in crude oil can be known.

Selecting an exact and stable method to measure the AP-P4 concentration is an important step to obtain the accurate results. There are plenty of detailed studies on the method of measuring the concentration of polyacrylamide polymers [7, 17-25]. The starch-cadmium iodide working curve method was often employed both in the oilfield and lab. Such method has some disadvantages, such as instability of absorbance and large errors originated from working curve method, and thus it cannot assure good repeatability. The estimate of total nitrogen is a kind of high temperature oxidation/chemiluminescence method, which can measure the total nitrogen content of all chemicals in water, is suitable for the accurate determination for nitrogen-contained compounds in simple lab systems. Its mechanism includes adding oxidant to the solution, decomposing the liquid samples in high temperature to oxidize all nitrogen atoms to $\mathrm{NO}_{3}{ }^{-}$, reducing $\mathrm{NO}_{3}{ }^{-}$to $\mathrm{NO}_{2}{ }^{-}$, producing purple azo compounds by chromogenic agent, obtaining the accurate concentration by UV spectrophotometer, and calculating the nitrogen content. The result is very reliable since there is no clay or undissolved substances in the simple lab system and also UV spectrophotometer measurement is rather accurate.

2.3. The Distribution of AP-P4 in Oil/Aqueous/Sand ThreePhase Systems. (1) The formation water of offshore oilfield SZ 36-1 was taken as reference; two kinds of simulative water were prepared. In sample A, the salinity was $17478 \mathrm{mg} \mathrm{L}^{-1}$. In sample $\mathrm{B}$, the salinity was $8739 \mathrm{mg} \mathrm{L}^{-1}$, a half of $\mathrm{A}$. The compositions are listed in Table 1.

The formation circumstance of SZ 36-1 was taken as reference, the solid/aqueous ratio was $1: 12$, and aqueous/oil ratio was $6: 4$.

(2) Simulative water A and B were taken, and the APP4 solutions were prepared, and diluted into a series of target concentration, ranged from $750 \mathrm{ppm}$ to $1750 \mathrm{ppm}$. The concentrations were calculated as the initial concentration $C_{01}$.

(3) $120.00 \mathrm{~g}$ AP-P4 solution was put along with $10.00 \mathrm{~g}$ sands into the $250 \mathrm{~mL}$ erlenmeyer flask, which was shaken until the mixture was uniformed. $80.00 \mathrm{~g}$ dehydrated crude oil was added into the erlenmeyer flask, which was shaken until the mixture was uniformed again. The three-phase system was oil/aqueous/sand from the top to the bottom. The erlenmeyer flask was sealed at the end.

(4) Put the $250 \mathrm{~mL}$ erlenmeyer flask in the oven at $65^{\circ} \mathrm{C}$ for $60 \mathrm{~h}$.

(5) Take out the erlenmeyer flask. Use hypodermic syringe and take out the clear liquid by suction. The clear liquid was stayed still until the small size sands were deposited.The nitrogen content of liquid was measured, and 


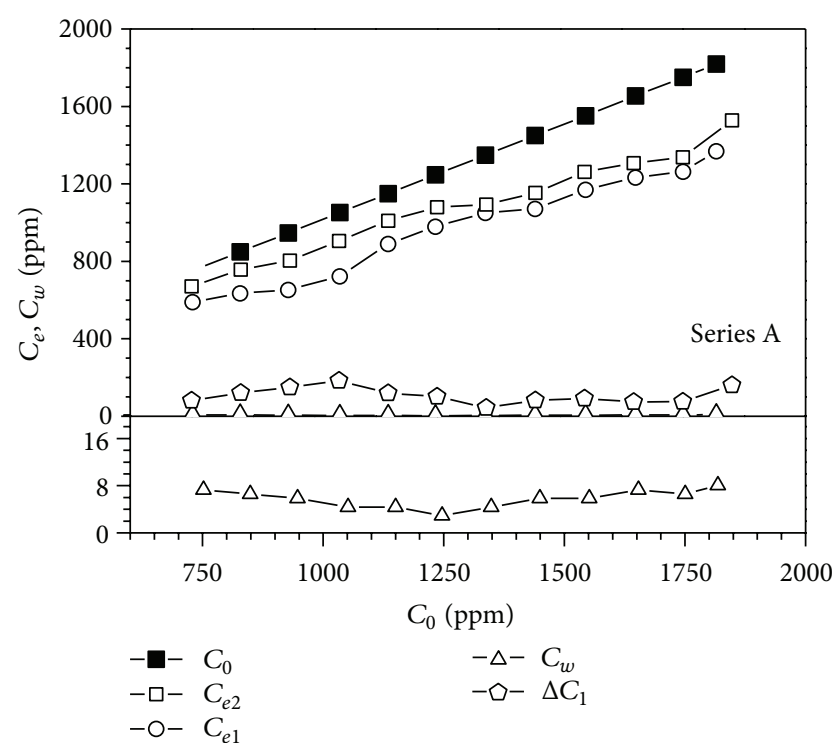

FIGURE 1: The adsorption experiment of two-phase and three-phase systems with the simulative water $\mathrm{A}$.

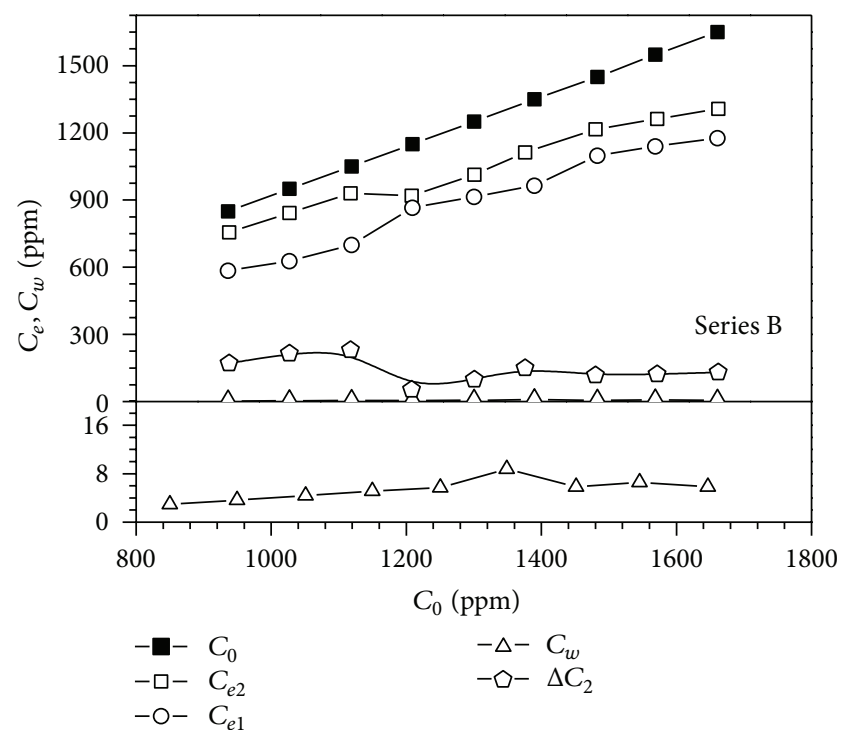

FIgURE 2: The adsorption experiment of two-phase and three-phase systems with the simulative water B.

the obtained data was the equilibrium concentration after adsorption, named as $C_{e 1}$.

The process (6) to (11) is to extract the polymer from the oil phase and to estimate the concentration of it.

(6) The oil obtained from the erlenmeyer flask after adsorption was filled into the electric dehydrate bottle. After that, the oil phase was dehydrated.

(7) $40.00 \mathrm{~g}$ water and $40.00 \mathrm{~g}$ dehydrated oil were filled into a $150 \mathrm{~mL}$ erlenmeyer flask. Shake the erlenmeyer flask and mix them thoroughly.

(8) Put the $150 \mathrm{~mL}$ erlenmeyer flask in the oven under $65^{\circ} \mathrm{C}$ for $24 \mathrm{~h}$. Shake them every $2 \mathrm{~h}$ to make the two-phase contact.
(9) Take out the $150 \mathrm{~mL}$ erlenmeyer flask. The clear aqueous phase at the bottom was taken out by the suction of hypodermic syringe.

(10) $10 \mathrm{~mL}$ aqueous phase was put in a beaker; the glacial acetic acid and sodium hypochlorite solution were added into it. The nephelometry was adopted to evaluate the existence of polymer [25].

(11) The oil phase was washed by water for the second time, and the nephelometry was carried out again until no turbid was observed.

(12) The aqueous phases that were extracted from the oil phase at two times were combined together. The total nitrogen estimates were carried out, and the obtained concentrations were $C_{w}$.

\subsection{The Distribution of AP-P4 in Aqueous/Sand Two-Phase} System. In the reported works, the adsorption of AP-P4 in queous/sand two-phase systems had been frequently studied to evaluate the adsorption and retention properties $[15,26]$. In this work, similar experiments had been done as a blank test in order to make comparison with three-phase systems for full research.

(1) Simulative water A and B are prepared, the compositions are same as Table 1.

(2) AP-P4 polymer solutions were made same as in the three-phase experiments, with the concentrations from $750 \mathrm{ppm}$ to $1750 \mathrm{ppm}$. The concentration was calculated and named with $C_{02}$, and herein the $C_{02}$ was prepared to be nearly $C_{01}$.

(3) Put $120.00 \mathrm{~g}$ AP-P4 solution along with $10.00 \mathrm{~g}$ sands into the $250 \mathrm{~mL}$ erlenmeyer flask.

(4) Put the $250 \mathrm{~mL}$ erlenmeyer flask in the oven and stay still under $65^{\circ} \mathrm{C}$ for $60 \mathrm{~h}$.

(5) Take out the erlenmeyer flask. Use hypodermic syringe and take out the clear liquid by suction. The clear liquid was standing until the small sized sands were deposited. The nitrogen content of liquid is measured, and the obtained data was the equilibrium concentration after adsorption, named as $C_{e 2}$.

\section{Results and Discussions}

3.1. The Equilibrium Concentration Curve. By using two kinds of simulative waters (A and B), three-phase static adsorption experiments and two-phase static adsorption experiments were carried out with oil, water, and sand.

As shown in Figures 1 and 2, the curve $C_{0}$ represents the initial concentration of the AP-P4 polymer solution in simulative water $\mathrm{A}$ and $\mathrm{B}$, respectively. As the proceeding of static adsorption, the concentrations of the AP-P4 are gradually reduced. The curve $C_{e 1}$ represents the equilibrium concentration of AP-P4 in the three-phase systems that remained in aqueous phase after static adsorption and the curve $C_{e 2}$ represents the ones in two-phase systems. $C_{w}$ is the AP-P4 concentration extracted from the oil phase after static adsorption, which is only a few ppm and is three orders 


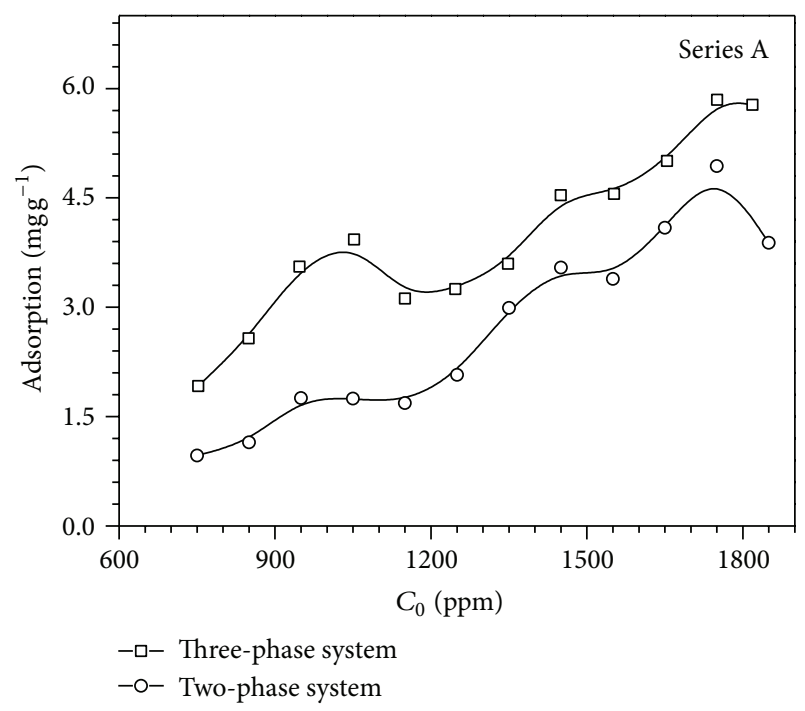

FIGURE 3: The isothermal adsorption of AP-P4 on the solid phase of two-phase and three-phase systems in the simulative water A.

of magnitude lower than $C_{e 1}$ and $C_{e 2}$. The fluctuation of the curve $C_{w}$ is very small and does not represent the trend of the distribution process. $\Delta C$ is the difference between the equilibrium concentration of $C_{e 1}$ and $C_{e 2}$, which is caused by the added crude oil. As been confirmed that there is no solubility of AP-P4 in the oil phase, and the adsorption ability of quartz is stable, there is no transfer of AP-P4 from aqueous phase to the oil phase or the solid phase. In this way, the shift of $\Delta C$ has two possible paths: one is the interface between the water phase and the oil phase and the other is emulsion phase formed by the mixture of water and the oil. Although the polymer has little dissolution in the crude oil, the introduction of the crude oil induced a distinct transfer and enrichment of AP-P4 around the interlayer region. In the AP-P4 flooding oilfield, there are large number of oilwater interfaces in the produced fluid, which are usually composed of polymer AP-P4, oil, and aqueous phase. These intermediate phases are always exhibiting relatively stable properties within a certain period of time. Compared to the water/solid two-phase systems that are normally studied in laboratory, the novel experimental method in this work is a more accurate way to reflect the true situation in oilfield.

3.2. Isothermal Adsorption Curve. After analysis of the experimental data in two salinity environments, the three-phase systems and two-phase systems isothermal adsorption curves on the solid phase were calculated, as shown in Figures 3 and 4 .

During the static adsorption process, the polymer molecules transferred from the aqueous phase to the surface of sands. For the two kinds of simulative water, the polymer adsorption behaviors under different concentrations are shown in Figures 3 and 4. The amount of the AP$\mathrm{P} 4$ adsorption at the surface of the quartz sands appears stepped growth process along with the increment of initial

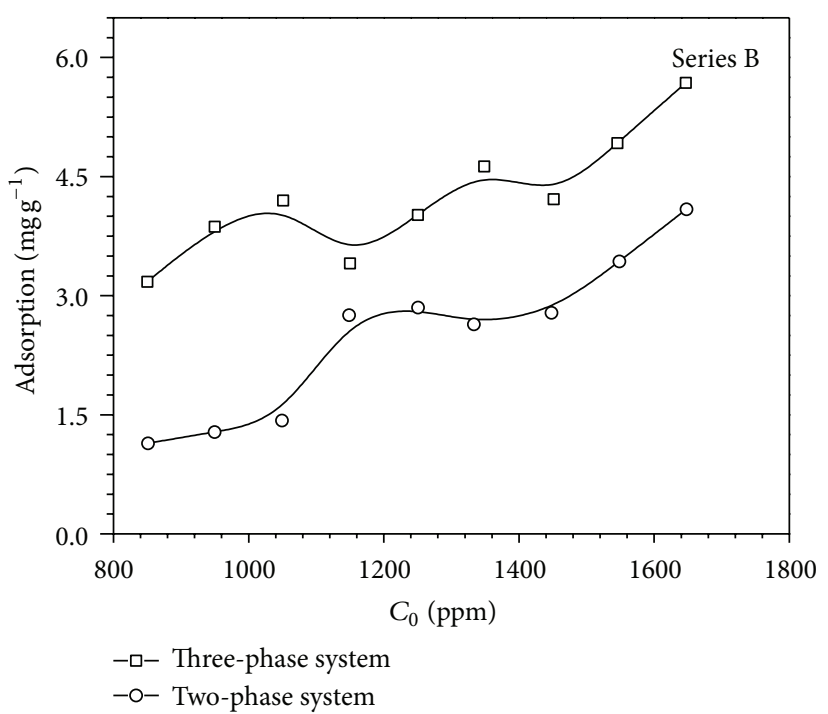

FIgURE 4: The isothermal adsorption of AP-P4 on the solid phase of two-phase and three-phase systems in the simulative water B.

concentration. It could be observed from the comparison of Figures 3 and 4 that the increment of the salinity could cause a significant increase in the amount of polymer adsorption on sands.

3.3. The Distribution Coefficient of Polymer AP-P4 in WaterSands System. For the two kinds of simulative water, the distribution coefficient of the AP-P4 in water-sands phases could be calculated, as shown in Figures 5 and 6 . The distribution coefficient is between 0.12 and 0.46 for simulative water $\mathrm{A}$ and between 0.12 and 0.52 for the simulative water $\mathrm{B}$. The distribution coefficients of AP-P4 in water- sands phases are fully consistent in trends in two salinity systems.

The variation of salinity affects the performance of APP4 from the comparison of Figures 5 and 6. The distribution coefficient in water-sands system becomes higher in simulative water A and lower in simulative water B, which implies that AP-P4 exhibits excellent salt resistance behavior. These properties are consistent with the results that have been reported [5, 12-14, 27].

It could be easily observed from the isothermal adsorption curve that the adsorption of AP-P4 on the sands exhibits a step shaped increment rather than Langmuir curve, which implies the variation of energy. The adsorption of polymer was caused by the fragment adsorption. When the polymer concentration is low, single layer adsorption occurred, the surface of sand was occupied by the polymer molecules, and the surface energy gets decreased. The repulsive interaction was emerged between adsorbed molecules and the surrounding molecules along with the increase of polymer concentration. As a result of repulsion, the surface energy gets raised and the step of adsorption curve occurs. The further increase of polymer concentration could facilitate the association between the adsorbed molecules and the molecules in aqueous, which results the second layer adsorption of 


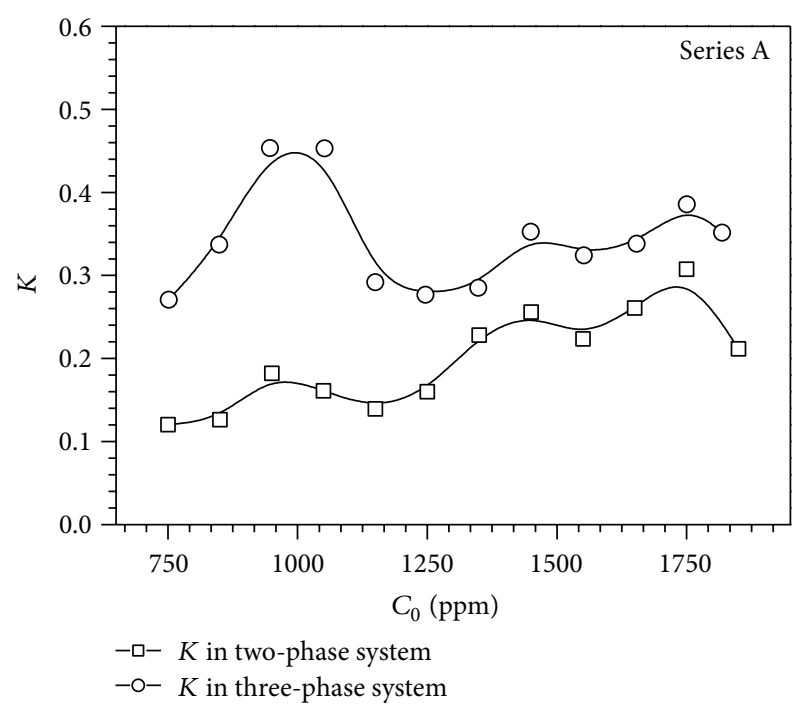

Figure 5: The distribution coefficient in water-sands system in the two-phase and three-phase systems in the simulative water A.

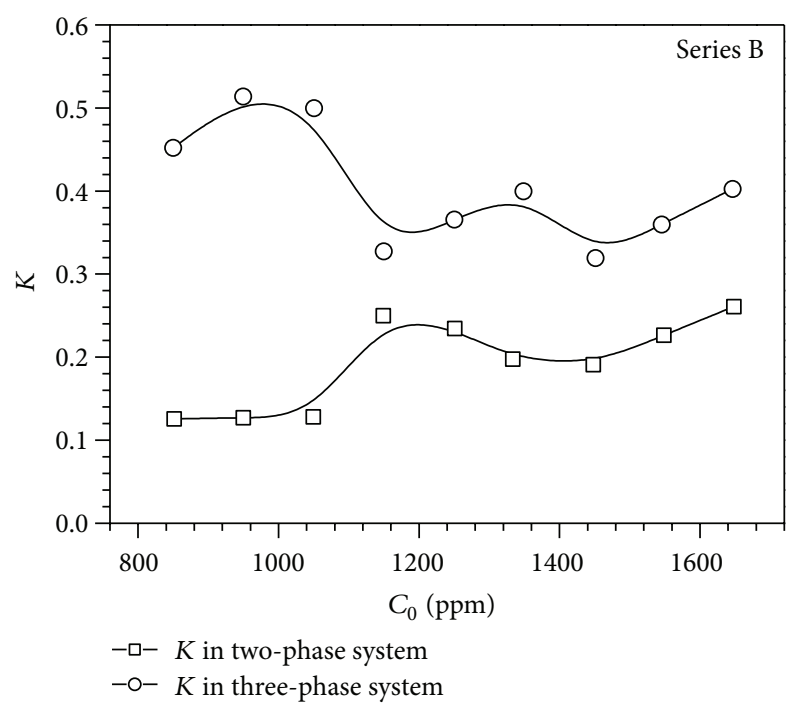

FIGURE 6: The distribution coefficient in water- sands system in the two-phase and three-phase systems in the simulative water B.

polymer molecules. The surface energy gets raised again and the step of adsorption curve occurs.

3.4. The Distribution Coefficient of Polymer AP-P4 in the Water-Oil System. The distribution coefficient $K$ of the AP$\mathrm{P} 4$ in water-oil system is defined as the proportion of AP-P4 concentration in the oil phase and water phase $\left(K=C_{w} / C_{e 1}\right)$, and can be calculated from the experiment results, as shown in Figures 7 and 8.

The distribution coefficients of AP-P4 in water-oil system range from 0.003 to 0.0124 for simulative water $\mathrm{A}$ and from 0.005 to 0.009 for simulative water $\mathrm{B}$. The $C_{w}$ is much lower than the $C_{e}$, so the calculated distribution relationship has confirmed that polymer does not dissolve in the oil phase.

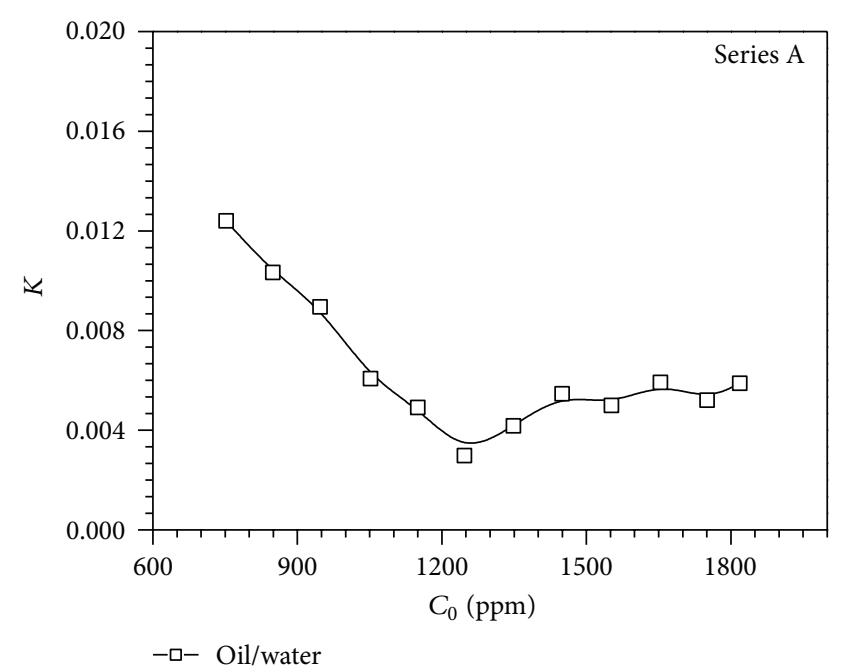

FIgURE 7: The distribution coefficient in water-oil system in the simulative water A.

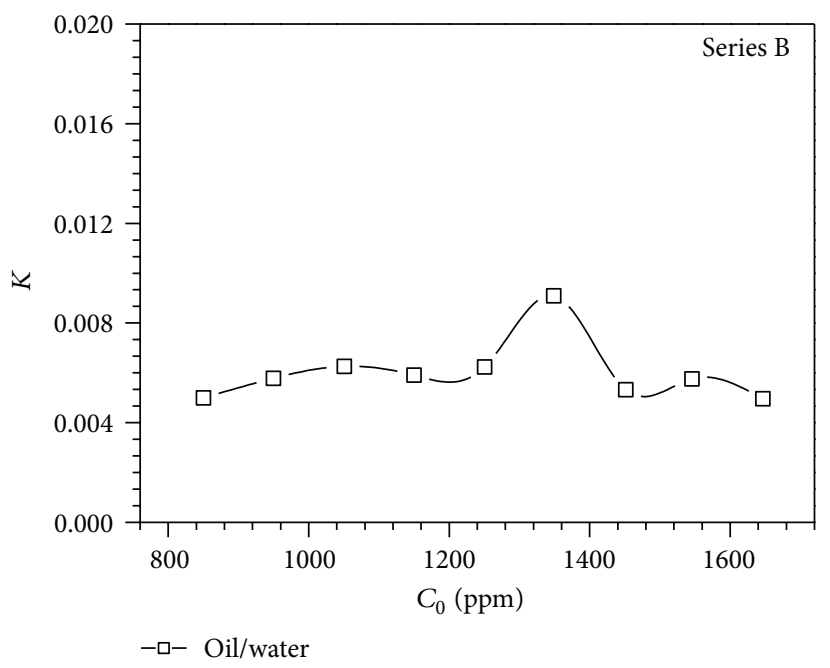

FIGURE 8: The distribution coefficient in water-oil system in the simulative water $\mathrm{B}$.

The enrichment of AP-P4 between aqueous and oil phase obeys the laws of polymer adsorption and hydrophobic adsorption. The molecular structure of AP-P4 is consisted with the HPAM skeleton and a little hydrophobic function groups (1-5\%). The polarity of hydrophobic function groups is weak, which make it impossible to form the hydrogen bonds with water molecules. So the chemical potential of these hydrophobic function groups is very high, and the solubility in aqueous phase is low. The hydrophobic microdomains are easily formed in aqueous phase, and the reorientation of molecules is easily occurred when the oil phase is added. The AP-P4 molecules stay in the aqueous phase while the hydrophobic function groups are pointed to the oil phase. In this way, the molecules are enriched between oil/aqueous interface. 
3.5. The Potential Utilities of the Experiment Methods. The solubility of polymer in oil phase is very low, so the former experiments on polymer static adsorption focus on the competing enrichment regulations between aqueous and solid phases. By using the experiment method in this work, the obtained distribution of AP-P4 among three-phase systems indicates the function of oil phase, which influence the orientation and distribution of polymer molecules. Values of $\Delta C$ were observed by the comparison of the obtained aqueous polymer concentration in three-phase systems $C_{e 1}$ and $C_{e 2}$ in two-phase systems. The value of $\Delta C$ is around $200 \mathrm{ppm}$ and has no responds on the variation of aqueous concentration. The experiment method is a more comprehensive and precise way to descript the reorientation and distribution of polymer molecules under the interactions of multiphase after injecting into the formation.

The obtained data could be helpful to simulate the regulation of the concentration loss during the polymer flooding. The viscosity of solution and displacement efficiency are high when the polymer solution was injected into the formation. However, after the adsorption and retention process, the adsorption of polymer would be nearly saturated around the injection point, the RF and RRF would be raised, and the following water driven efficiency would be raised. During the migration of polymer solution, the concentration gets lowered in the deep side of formation, so does the saturated adsorption amount. The modification of RF and RRF decreased too. By using the data obtained in this work, the decrement regulation of polymer concentration and the ability of the formation modification could be simulative by numerical modeling. Besides, the variation of oil displacement and swept ability could also be predicted.

Plenty of emulsion phases existed in the oilfield produced water, for the enrichment trend of AP-P4, to control the water cut of crude oil and the oil content of sewage is one of the most important issues. In the process of produced water treatment, the pertinence methods would be adopted in order to enhance the dehydration efficiency and to prevent the failure of electric dehydration. In this work, the effect of oil phase on polymer distribution was taken into consideration. The comparison of the results from three-phase system and two-phase system could help to understand the polymer content in emulsion phase and the enrichment status of polymer molecules, which would provide the basis of the usage and dosage of demulsifier.

\section{Conclusions}

(1) A novel experiment method was designed to estimate the distribution of hydrophobic associated polymer AP-P4 among three-phase systems. The adsorption experiments were carried out in oil/aqueous/solid system, and the comparison experiments with aqueous/solid two phases were carried out too. By using the experiment method, the distribution behavior of AP-P4 among oil/aqueous/solid system was obtained, and the influence of mineralization polymer concentration was revealed.
(2) The experiment method is different from the former adsorption experiments in two-phase systems, which could reveal a more comprehensive character of the system. Although there is no solubility of polymer in oil phase, significant affection had been done on the distribution of polymer molecules by the existence of oil phase.

(3) A distinct decrease of polymer concentration was observed in aqueous phase by the experiment method, which could be induced by the enrichment of polymer molecules on the oil/aqueous interface under the appearance of oil phase. The enrichment of polymer could be estimated by evaluating the emulsion phase, which could help to understand the enrichment and the concentration of polymer molecules in the emulsion phase.

\section{Acknowledgment}

The authors gratefully acknowledge the financial support from subject 4 "Chemical Flooding Technology for Offshore Heavy Oil" (2011ZX05024-004) that belongs to project 24 "New and High Effective Development Technique for Offshore Heavy Oil" of Natural Science and Technology Major Project "Development of Large Field and Coal Bed Methane" in 12th five-year plan.

\section{References}

[1] N.-J. Lai, Y. E. Zhongbin, Y. Zhou, and T. Jia, "Study on solution properties of new hydrophobic associated polymer and enhanced oil recovery," Petroleum Geology and Recovery Efficiency, vol. 12, no. 2, pp. 63-65, 2005.

[2] Y.-F. Wang, H.-Y. Yu, J. Zhang, W. H. Chen, and S. L. Wang, "Study on decompression and augmented injection by surfactants during hydrophobically associating polymer flooding in Bohai Oilfield," Zhongguo Shiyou Daxue Xuebao, vol. 34, no. 6, pp. 151-156, 2010.

[3] H. Ren, Z. Luan, Z. Li, and Z. Yang, "Enrichment of polycyclic aromatic hydrocarbons by hydrophobically associated polymers," Environmental Chemistry, vol. 30, no. 2, pp. 471-475, 2011.

[4] L. Yang and J. Zhang, "The effect of inorganic salts on the adsorption of amphoteric ion polymer on clay surface," Journal of Southwest Petroleum Institute, vol. 19, pp. 49-52, 1997.

[5] X. Song, G.-Y. Yang, and J. Ke, "Enthalpy of adsorption and adsorption isotherms of polyacrylamide on oil sand," Chinese Chemical Society, no. 1, pp. 39-41, 1998.

[6] G. Liu, "The adsorption property of polymers on the solids of clay and drilling fluid," Environmental Protection of Oil \& Gas Fields, vol. 9, pp. 38-41, 1999.

[7] B.-Z. Mu and P.-Y. Luo, "Experimental methods and techniques for determining adsorrtion behavior parameters of polymers at solid/liquid interfaces," Oilfield Chemistry, vol. 16, no. 1, pp. 9798, 1999.

[8] Y.-J. Guo, F.-S. Li, and L.-H. Li, "Adsorption behavior of water-soluble hydrophobic associated polymer at water/kaolin interface," Chinese Journal of Applied Chemistry, vol. 19, pp. 26$28,2002$. 
[9] J.-S. Miao, F.-L. Zhao, S. Li, Y.-H. Yu, and M. Chen, "Presence and distribution of residual polymer in formation," Special Oil \& Gas Reservoirs, vol. 12, pp. 88-90, 2005.

[10] K. Ren, G. Jiang, M. Lin, and C. Xu, "Influence of salt concentration on the properties of the hydrophobically associated polymer solution," Journal of Functional Polymers, vol. 2, pp. 321-324, 2005.

[11] J.-P. Shi, Q.-Y. Yang, and C.-F. Liu, “The experiment of influence of polymer absorbance in the properties of formation," Journal of Oil and Gas TEchnolory, vol. S1, pp. 224-227, 2005.

[12] C.-J. Zhou, H.-B. Li, and C.-Q. Shu, "Measuring the static state adasorption isotherm of the hydrophobically associated polymer on oil sand in suizhong oilfield," Offshore Oil, vol. 25, pp. 27-30, 2005.

[13] J.-Z. Zhou, Y.-Z. Zhao, and C.-Y. Zhang, "Study of the adsorption of surfactant,polymer and alkali on the surface of solid particle by XPS," Applied Chemical Industry, vol. 37, pp. 713-716, 2008.

[14] D.-S. Li, J.-R. Hou, and J.-R. Hou, "Adsorption of components from ASP flooding solution onto reservoir rock of Daqing," Oilfield Chemistry, vol. 18, no. 4, pp. 358-382, 2001.

[15] J.-F. Zhang, The behavior of adsorption and retention and characteristic of flowing through the porous media of hydrophobically associated polymers [M.S. thesis], 2004.

[16] H.-J. Zhu, J.-H. Luo, and J.-B. Yang, "Three key factors influencing oil-displacement capacity in hydrophobically associating polymer flooding," Acta Petrolei Sinica, vol. 26, no. 3, pp. 52-55, 2005.

[17] S.-X. Guan, H.-F. Fan, and J.-G. Duan, "Starch-cadmium iodide, the estimate method of concentration of HPAM," Journal of Daoqing Petroleum Institute, vol. 31, no. 12, pp. 110-112, 2007.

[18] C.-Q. Hong, Z.-B. Ye, L.-T. Shi, C. Zhang, and Z.-C. Yang, "Research on solution property and evaluation method of polymer gels and hydrophobic associated polymer," Oil Drilling \& Production Technology, vol. 29, pp. 61-64, 2007.

[19] B.-L. Kong, "A review on methods for determing hpam concentration of aqueous solutions," Oilfield Chenmistry, vol. 13, no. 3, pp. 284-288, 1996.

[20] B.-L. Kong and H.-C. Zhang, "Determination of hydrolysis degree of polyacrylamide by starch-trhodide method," Oilfield Chemistry, vol. 14, no. 1, pp. 73-76, 1997.

[21] X.-B. Nie, J. Liu, and Q. Qiao, "An improved method for quantitative analysis of hpam in asp-flooding," Oilfield Chemistry, vol. 14, no. 4, pp. 369-371, 1997.

[22] C. Yang, R. K. Wu, P.-D. Zhu, and X. R. Yang, "Determination of total nitrogen in water using high temperature oxidation \& chemiluminescence method," Chinese Journal of Analytical Chemistry, vol. 35, no. 4, pp. 529-531, 2007.

[23] Z.-G. Ye and Z.-G. Cui, "Preparation properties and characterization of inorganic nano-scale materials," China Surfactant Detergent \& Cosmetics, vol. 34, no. 1, pp. 52-54, 2004.

[24] Q. You, F.-L. Zhao, L.-N. Mu, L. He, and Y. P. Jia, "A new method for the accurate determination of polyacylamide concentration in produced fluids of ploymer flooding oil well- a film drying method after ultrafiltration and condensation," Acta Petrolei Sinica, vol. 23, no. 1, pp. 109-113, 2007.

[25] B.-C. Zhao and G.-X. Zhang, "Determination of hydrolysis degree and concentration of HPAM by nitrogen determination method," Oilfield Chemistry, vol. 2, no. 3, pp. 233-235, 1985.

[26] X.-N. Li, Z.-B. Ye, H. Chen et al., "Effect of polymer on crude oil demulsification," Advances in Fine Petrochemicals, vol. 7, pp. 15-17, 2006.
[27] J.-F. Zhang, Z.-B. Ye, and Z.-J. Li, "Adsorption behavior of hydrophobic associated polymer (Hap) in quartz sands," Natural Gas Eaploration \& Developmaent, vol. 27, pp. 48-51, 2004. 

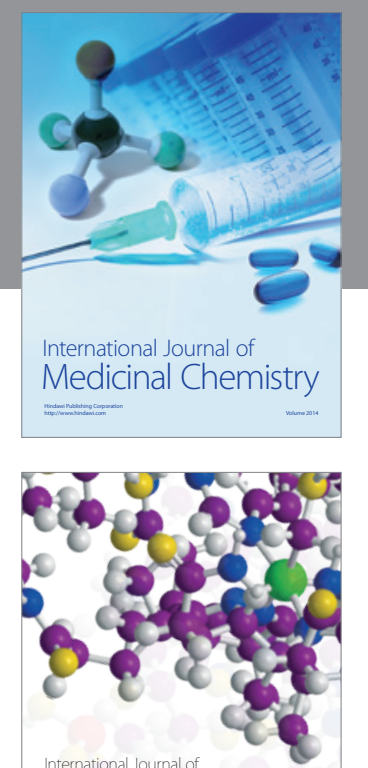

\section{Carbohydrate} Chemistry

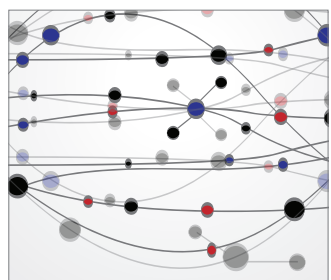

The Scientific World Journal
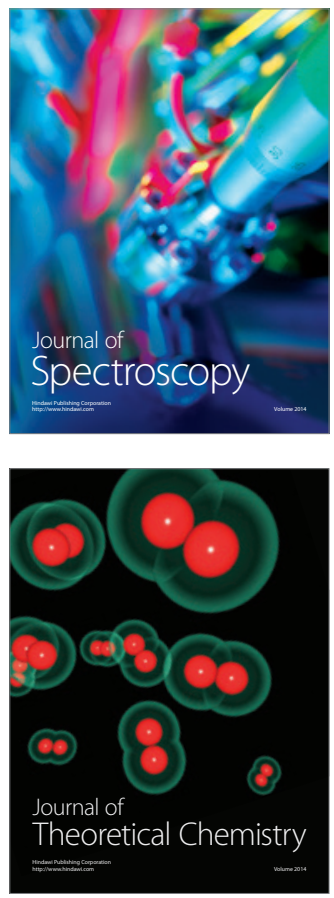
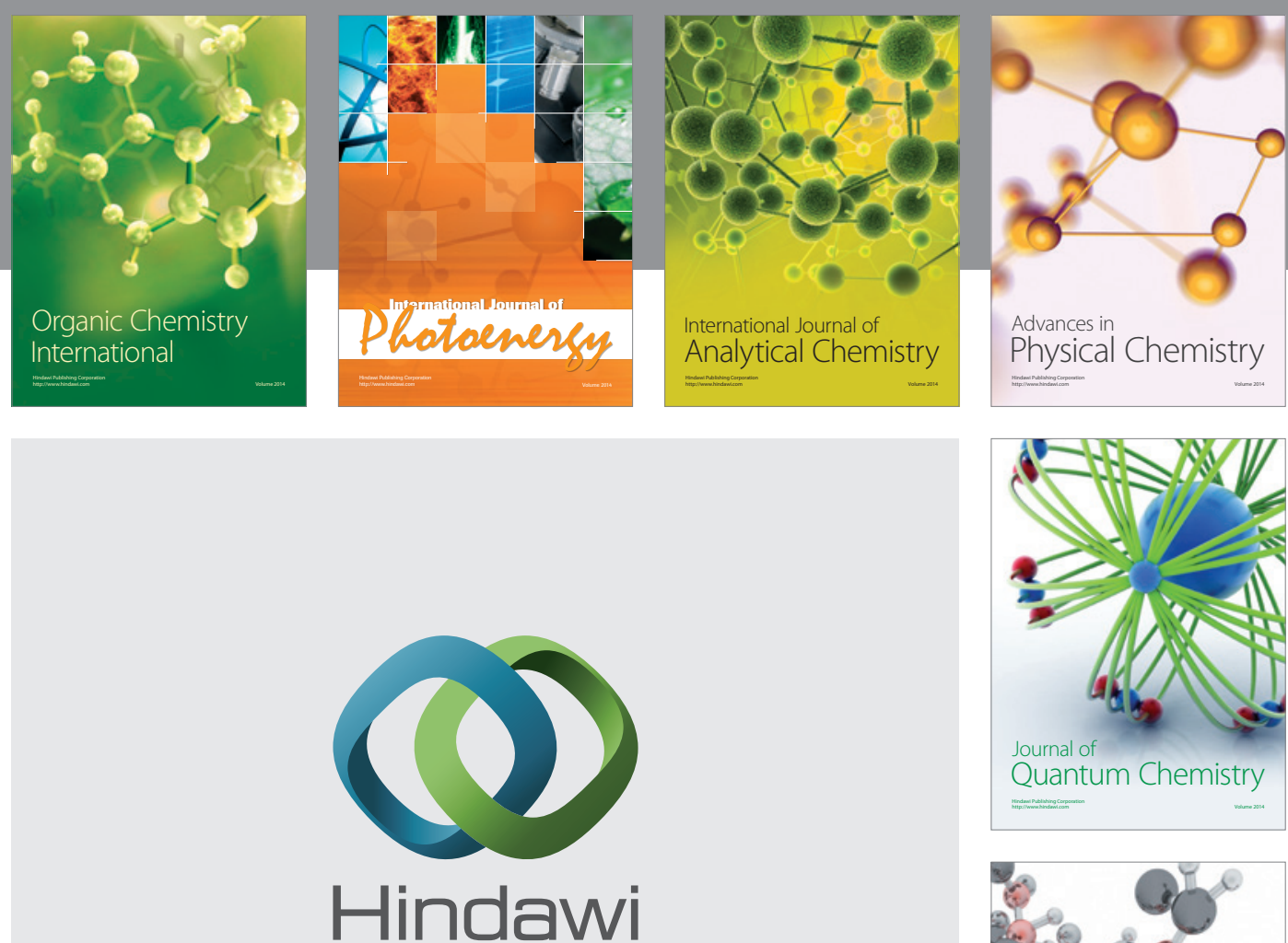

Submit your manuscripts at

http://www.hindawi.com

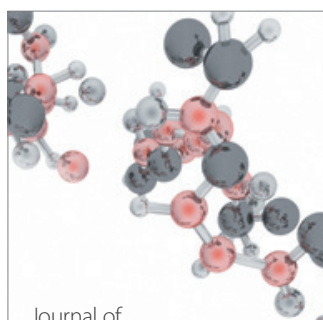

Analytical Methods

in Chemistry

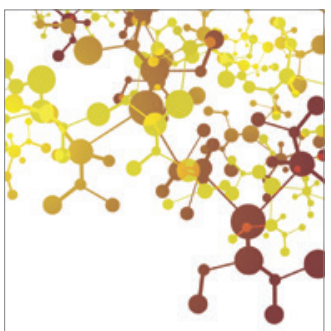

Journal of

Applied Chemistry

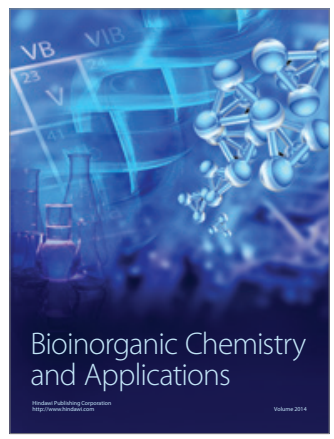

Inorganic Chemistry
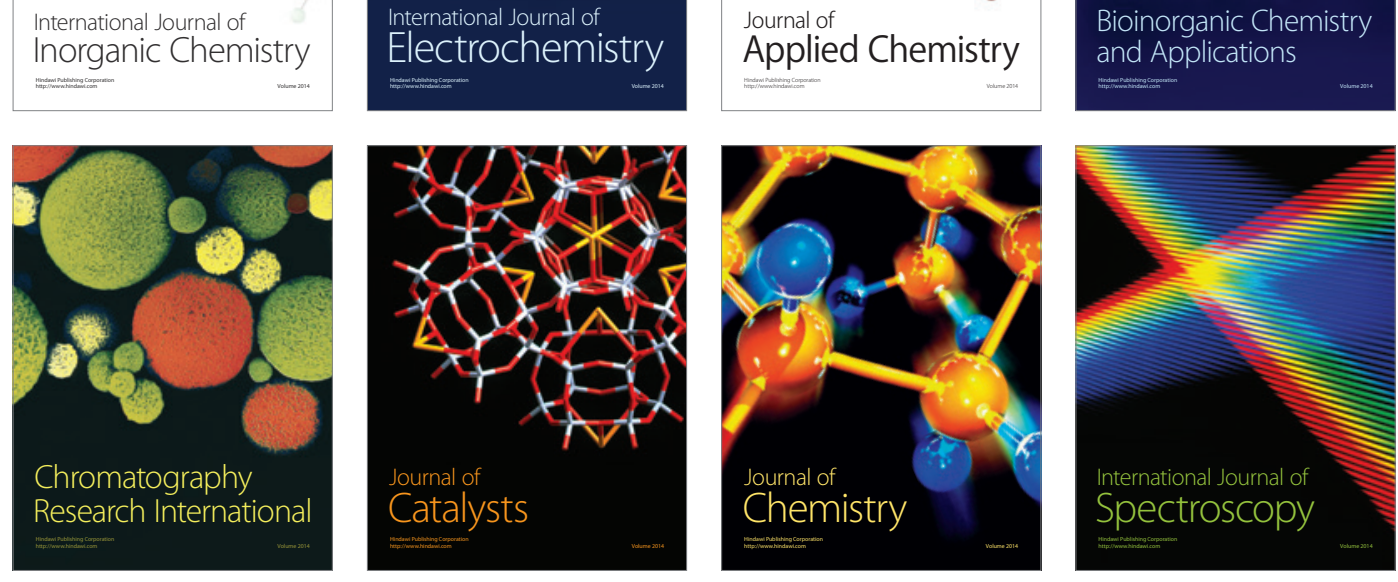